\title{
Experimentellt framkallad sorgsenhet kastar nytt ljus över suicidalitet
}

\author{
Ved Jan Beskow
}

\section{När någon tagit sitt liv kommer smärtsamma minnen. Bland de smärtsammaste hör svårigheterna att få hjälp. Ingen verkade förstå vad som höll på att hända. Varför var det så?}

Läkare uppmärksammar det sjuka. Det är deras jobb. De uppfattar suicidtankar som ett depressionsymtom. Detta understryks av att döds- och suicidtankar är ett av nio kriterier på depression i systemet för klassifikation av psykiska störningar, DSM -IV. D et är lätt att föreställa sig en process från lindrig, till djupare, till den djupaste depression och först då kommer suicidiet. M en detta stämmer inte. $M$ änniskor tar sina liv när som helst under pågåen de depressioner. De kan vara obetydligt deprimerade eller djupt deprimerade. De kan också ta sitt liv just när depressionen verkar gå över. Suicidaliteten (suicidtankar, planer, suicidförsök, fullbordade suicid) verkar delvis leva sitt eget liv, vara en egen process. G rundat på kliniska observationer har suicidforskare länge hävdat detta. N u kommer den vetenskapliga kunskapen steg för steg.

\section{Fångad i en àtervändsgränd}

Den grundläggande bilden, metaforen, är hämtad från djurlivet: En revirstrid mellan fåglar (W illiams, 2001). Den som förlorar sänker vingarna och huvudet, gör sig liten, backar bakåt, markerar underkastel se. U ttrycken är desamma som en människa som överväldigas av skam. Finns det gott om platsi skogen flyger förloraren dit och upprättar ett nytt revir. Då går symtomen fort över. Lyckas den ej med det kvarstår "depressionen". Funktionsförmågan är allvarligt nedsatt och risken att gå under, att dödas, i den hårda livskampen är stor.
Denna bild av instängdheten består av tre delar: A tt förlora, att flyktvägarna är stängda och att ingen hjälp är i sikte. Det påminner slående om en klassisk metafor för den suicidala situationen: En psykiskt plågad människa, instängd i ett hörn utan att se någon utväg. I en sådan situation uppkommer ofta en känsla av skam. Dess djupaste natur är upplevelsen av att vara övergiven eller utstött, av att inte längre höra till de andra i gruppen. Den inre känslan av skam kan vara stark utan att det märks utåt. O rsakerna kan vara inre faktorer, obegripliga för utomstående. I denna smärtsamma upplevelse kan suicidiet te sig lockande, som en möjlig befrielse. (W illiams, 2001)

Det finns nu både psykologiska tester och behandlingsmetoder för de olika komponenterna i detta tillstånd. O rdet "behandlingsmetoder" för lite fel. Det handlar om att personen själv skall förstå sitt tillstånd och få verktyg så att hon kan hantera det.

\section{Positiva effekter av suicidförsök}

Det har länge varit känt att suicidförsök ger upphov til vad man kallar katharsis, dvsen oväntad känsla av frihet och glädje. Det är som man plötsligt blivit befriad från alla tunga tankar som fängslat och bundit en. Detta har beskrivits både för suicidförsök med tabletter (A Ivarez, 1974) och genom hopp från $\mathrm{G}$ olden $\mathrm{G}$ ate-bron i San Francisco (R osen, 1999). Denna upplevelse har man nu lyckats fånga i psykologiska tester (W illiams, 2004).

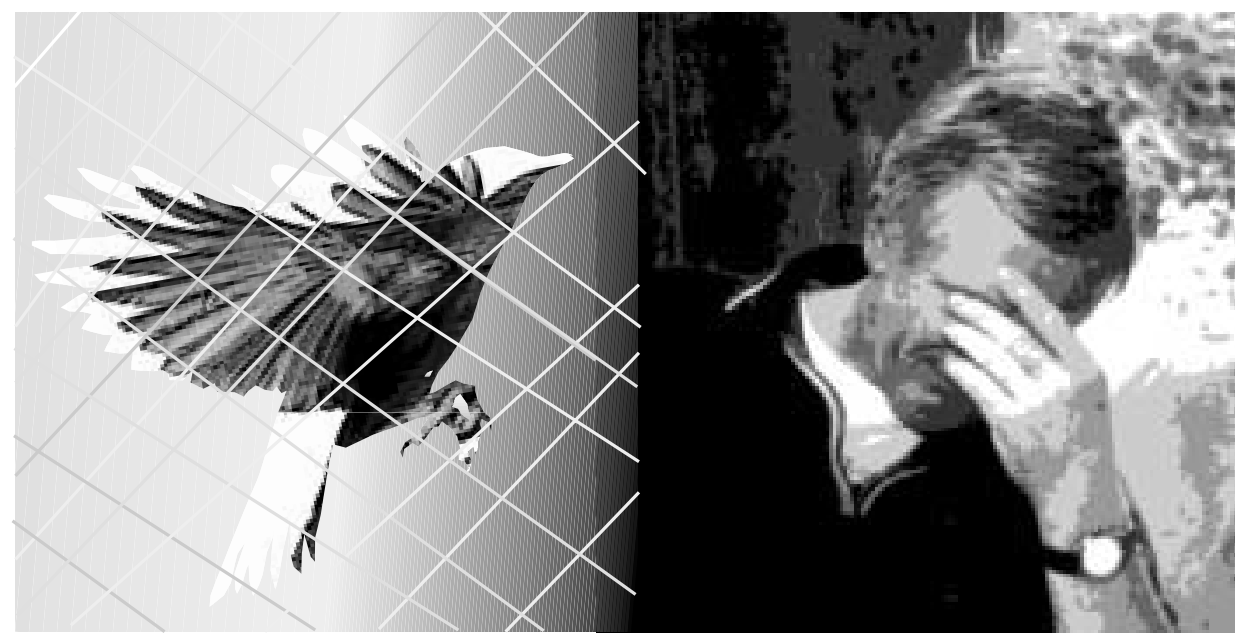

Suicidtankar uppkommer när en person sitter fast i problem som hon inte kan lösa. Efter upprepade misslyckanden uppstår en känsla av hopplöshet. Sedan länge finns skalor för att mäta både denna hopplöshet (höga poäng = hög grad av hopplöshet) och förmågan att lösa problem ( höga poäng = god problemlösningsförmåga). Det nya är att man nu gjort sådana mätningar ett dygn, en vecka och sju veckor efter ett suicidförsök. Vid första mätningen ligger poängen för hopplöshet högt. Den sjunker dock drastiskt inom en vecka. Förmågan att lösa problem är låg alldel es efter suicidförsöket, men ökar sedan drastiskt. De goda effekterna kvarstår många veckor efter suicidförsöket. Förändringarna är lika stora och ibland större än de man kan åstadkomma genom psykoterapi. O m man överlever är således själva suicidförsöket ett verksamt botemedel mot det de psykiska plågorna. En liknande positiv effekt på ångesttillstånd är vanligt bland unga flickor, som skär sig. De upprepar därför skärningarna vid nya ångestattacker.

\section{Sorgsen sinnesstämning}

Ett suicidalt tillstånd kan således vara snabbt övergående. D etta leder till frågan: Kan det också dyka upp lika snabbt? Detta har man nu kunnat studera experimentellt på friska försökspersoner (W illiams, 2004). G enom att spela sorgsen musik, genom att visa sorgsna avsnitt från vanliga spelfilmer eller genom att be försökspersonen erinra sig en situation då hon känt sig riktigt sorgsen var det inte svårt att framkalla en allmän känsla av sorgsenhet. Efteråt fick försökspersonerna fylla i en skala, som mäter upplevelser av suicidtankar. N ärvaron av psykologiskt tränad personal gjorde att suicidtankarna kunde fångas upp och bearbetas innan personen lämnade försökslaboratoriet.

Det visade sig att personer som haft depressioner utan tidigare suicidalitet reagerade på samma sätt som personer som aldrig varit deprimerade, dvs den sorgsna sinnesstämningen gav inte upphov till några suicidtankar. Personer som haft depressioner med suicidalitet reagerade däremot i stor utsträckning med suicid- 
tankar trots att de nu var friska. Detta understryker betydelsen av att studera suicidalitet och depressioner var för sig. A nnars upptäcker man aldrig hur dessa tillstånd samspelar med varandra. Det är också tydligt att även lätta former av sorgsen sinnesstämning kan ge upphov till suicidtankar. Detta kan förklara varför suicidhandlingar ibland sker i ett friskt skede. "M en varför just nu? $\mathrm{H}$ an mådde ju så bra."

Sorgsen sinnestämning utlöser således suicidtankar även i friska intervall. Det är ett tillstånd, state, som uppkommer på basen av en benägenheten att lätt få suicidtankar, ett trait. Detta karaktärsdrag kan vara beroende av genetisk läggning. Framför allt torde dock tidigare framgångsrika erfarenheter av att lösa problem lett till uppkomsten av sätt att tänka, kognitiva strategier, som sedan blivit vanor, scheman. M en i annorlunda mer utsatta situationer räcker inte dessa alltid till, de blir dysfunktionella. Det gör att personen kör fast. D et finnsi dag både teorier och data som belyser de negativa effekterna av dysfunktionella tankestrategier. Det finns också effektiva behandlingsmetoder (C lark, 1999).

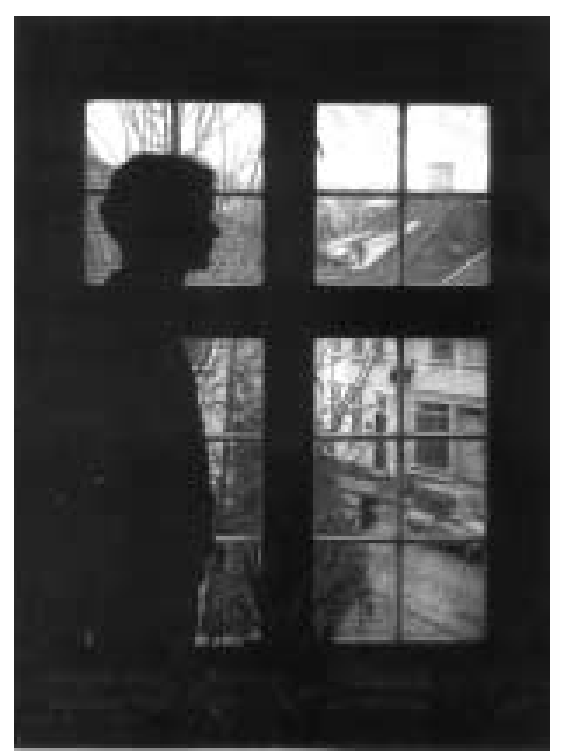

\section{Tankemodeller}

A tt se suicidalitet som symtom på depression är en tankemodell. A tt se suicidalitet som en process, som utvecklas under lång tid, är en annan. De här fynden ger snarare stöd åt en tredje modell, olycksfallsmodellen, uppfattningen att suicid utlöses av en tillfällig konstellation av psykiska stimuli, som personen just då inte lyckas hantera. Jämför trafikolycksfall, som utlöses av en tillfällig konstellation av fysiska krafter, som föraren just då inte lyckas hantera (Beskow, 1982).

Det är också viktigt att se att den nedsatta problemlösningsförmågan är en språklig fråga. Innan en person aktivt kan lösa sina problem måste hon med tankar och ord formulera hur lösningen skall se ut. Detta ger oss en fjärde modell: A tt se suicidalitet som språk. Dessa modeller är olika perspektiv på suicidalitet. De kan således finnas samtidigt.

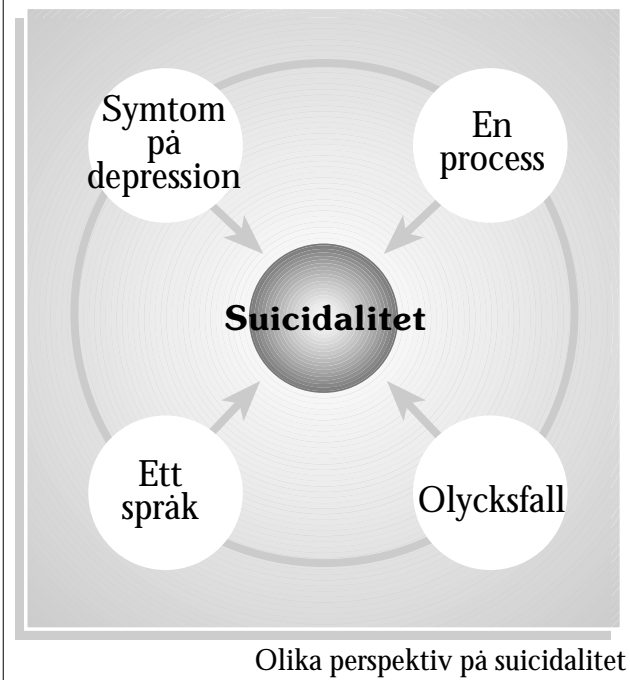

\section{Betydelse}

Känslor av instängdhet, hopplöshet och svårigheter att lösa sina problem kan ha funnits då och då under lång tid. M en plötsligt kan yttre intryck, ofta relativt obetydliga, utlösa en sorgsen sinnesstämning, som åter aktualiserar dessa känslor. A lkohol förstärker ytterligare denna tendens. Ett sätt att komma undan kan vara att fly in i döden. Då vet man ju dessutom att olusten aldrig mer kommer tillbaka. Den tanken kan ge en känsla av befrielse. Personer som överlever ett allvarligt suicidförsök kan direkt få uppleva denna befrielse. För en del är det en omskakande upplevelse av stor betydelse för deras fortsatta liv.

Suicidal iteten har här studerats för sig. Det ger en mångfasetterad bild, som inkluderar diagnostiska tester och konkreta behandlingsmetoder. R esultaten är begripliga både utifrån normala psykologiska mekanismer och utifrån vad vi tidigare vet om suicidalitet. Vilken betydelse de kommer att få för praktisk suicidprevention är för tidigt att bedöma. Personligen tror jag att de kommer att få stor betydelse för alla som själva av och till angrips av suicidtankar men också för deras anhöriga. De kan få ytterligare en pusselbit i sin förståelse av vad som egentligen hände vid ett suicidförsök resp. suicid. O lycksfal lsmodellen gör det också lättare att hantera skuldkänslorna. Ett stort och hängivet arbete måste nu göras för att dessa nya kunskaper skall fă ett genomslag också i hälso- och sjukvården.

\section{Referenser}

Beskow J. (1982). Longitudinal and transectional perspectives on suicidal behaviour. Experiences of suicide prevention in Sweden. I A chté K $\mathrm{N}$ ieminen K, Vikkula J. Suicide research II. Proceedings of the symposium on suicide research by the Yrjö Jahnsson foundation. Psychiatria Fennica suppl.

A Ivarez A . (1974). N är livet mist sin mening. O m självmord och självmordsförsök. Stockholm: Rabén \& Sjögren.

Clark D, Beck A , A lford B. (1999). Scientific foundations of cognitive theory and therapy of depression. N ew York: W iley.

Rosen D. (1999). D epression och skapande. H ur själen kan läkas genom kreativitet. Stockholm: $\mathrm{N}$ atur \& Kultur.

Williams M , Pollock L. (2001). Psychological aspects of the suicidal process. Kap $5 i$ van $\mathrm{H}$ eeringen $\mathrm{K}$ (red). U nderstanding Suicidal Behaviour. The Suicidal Process A pproach to Research, Treatment and Prevention. C hichester: W iley.

Williams M och andra. (2004). Symposier och föredrag vid European A ssociation for Behavioural $\&$ Cognitive Therapies: XXXIV A nnual Congress i M anchester, England, 9-11 september 2004.

Beskow J. (2005). Suicidalitetens språk.

Studentlitteratur (under publicering)

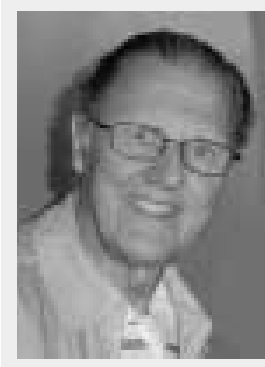

Jan Beskow är professor psykiatri. $\mathrm{H}$ an är ordförande i V ästsvenska nätverket för suicidprevention och verksam vid Center för Cognitiv Psykoterapi och U tbildning i G öteborg, och är nyss hemkommen från en konferensi $\mathrm{M}$ anchester. 